\title{
Effectiveness of nurse-delivered cardiovascular risk management in primary care: a randomised trial
}

\author{
Helene R Voogdt-Pruis, George HMI Beusmans, \\ Anton PM Gorgels, Arnold DM Kester and Jan W Van Ree
}

\begin{abstract}
Background

A substantial part of cardiovascular disease prevention is delivered in primary care. Special attention should be paid to the assessment of cardiovascular risk factors. According to the Dutch guideline for cardiovascular risk management, the heavy workload of cardiovascular risk management for GPs could be shared with advanced practice nurses.
\end{abstract}

Aim

To investigate the clinical effectiveness of practice nurses acting as substitutes for GPs in cardiovascular risk management after 1 year of follow-up.

Design of study

Prospective pragmatic randomised trial.

Setting

Primary care in the south of the Netherlands. Six centres (25 GPs, six nurses) participated.

Method

A total of 1626 potentially eligible patients at high risk for cardiovascular disease were randomised to a practice nurse group $(n=808)$ or a GP group $(n=818)$ in 2006 . In total, 701 patients were included in the trial. The Dutch guideline for cardiovascular risk management was used as the protocol, with standardised techniques for risk assessment. Changes in the following risk factors after 1 year were measured: lipids, systolic blood pressure, and body mass index. In addition, patients in the GP group received a brief questionnaire.

Results

A larger decrease in the mean level of risk factors was observed in the practice nurse group compared with the GP group. After controlling for confounders, only the larger decrease in total cholesterol in the practice nurse group was statistically significant $(P=0.01$, twosided).

\section{Conclusion}

Advanced practice nurses are achieving results, equal to or better than GPs for the management of risk factors. The findings of this study support the involvement of practice nurses in cardiovascular risk management in Dutch primary care.

\section{Keywords}

cardiovascular diseases; general practice; general practitioners; prevention; primary care; risk factors.

\section{INTRODUCTION}

In many parts in the world, including the Netherlands, cardiovascular disease (CVD) is a leading cause of death. In 2008, about $6 \%$ of Dutch citizens were diagnosed with CVD and 40587 Dutch died because of CVD; ${ }^{1-3}$ therefore, prevention of morbidity and premature death from CVD is of vital importance.

A substantial part of both primary and secondary prevention of CVD could adequately be delivered at the primary care level. Health professionals need to pay special attention to the assessment of cardiovascular risk factors. ${ }^{4,5}$ Some of the risk factors are used in risk calculations to assess the individual absolute cardiovascular risk score..$^{6-8}$ The individual risk is the starting point for the development of prevention strategies. It has already been argued that patients at high risk of CVD will benefit most from prevention strategies. ${ }^{9}$

According to the Dutch guideline for cardiovascular risk management, the heavy workload for GPs of cardiovascular risk management

HR Voogdt-Pruis, MSc, PhD student, Department of Integrated Care; GHMI Beusmans; PhD, MD, senior researcher, Department of Integrated Care and General Practice; APM Gorgels; PhD, MD, professor of integrated cardiology, Department of Cardiology; ADM Kester; PhD, statistician, Department of Methodology and Statistics; JW Van Ree, $P h D, M D$, professor of general practice, Department of General Practice, Care and Public Health Research Institute, Maastricht University Medical Centre/CAPHRI, Maastricht, the Netherlands.

Address for correspondence

Helene Voogdt, Maastricht University Medical Centre, Department of Integrated Care, Postbus 58006202 AZ

Maastricht, the Netherlands.

E-mail: helene.voogdt@mumc.nl

Submitted: 17 June 2009; Editor's response: 6 July 2009; final acceptance: 13 August 2009.

(c)British Journal of General Practice 2010; 60: 40-46. DOI: 10.3399/bjgp10X482095 
in primary care could be shared with practice nurses, supervised by GPs. ${ }^{5}$

Studies on care for the chronically ill have shown that task substitution from GPs to advanced practice nurses is effective..$^{10-14}$ In 2004, Laurant et al suggested in their Cochrane systematic review that trained nurses can achieve equally good health outcomes as GPs for different kinds of diseases. ${ }^{15} \mathrm{In}$ the Netherlands, however, there has been no study on the effectiveness of nurse-delivered cardiovascular risk management in the primary care setting.

The aim of the present study was to investigate whether practice nurses could act as substitutes for GPs in cardiovascular risk management for high-risk patients. It was hypothesised that practice nurses should be at least as good as GPs at achieving health outcomes after 1 year of follow-up. Primary outcome measures were the following risk factors: systolic blood pressure, cholesterol, smoking, and body mass index (BMI). It was not possible to use the risk score as a primary outcome measure, as the use of risk charts is inappropriate in patients with existing CVD. Before starting the trial, an exploratory study on the feasibility of cardiovascular risk management by practice nurses showed high satisfaction with care among caregivers. ${ }^{16}$

\section{METHOD}

\section{Study design}

This study was a prospective randomised trial at six healthcare centres (25 GPs, six practice nurses, approximately 30000 patients) in the south of the Netherlands. All participating healthcare centres already had an advanced practice nurse employed to manage patients with asthma, chronic obstructive pulmonary disease, or diabetes. Randomisation was computer generated at patient level within each healthcare centre. Zelen's design was used. GPs invited the patients selected for screening of risk factors. Scientific research was not mentioned in the invitation letter. Patients were asked for their consent after 1 year of follow-up. This was done to avoid situations where patients would fail to visit the healthcare centre for risk assessment because of their participation in a trial. Zelen's design is particularly used when evaluating the full unbiased impact of screening interventions. ${ }^{17-19}$

\section{Patient selection}

Patients eligible for this study were aged 30-74 years, with at least a $10 \% 10$-year risk of fatal CVD according to the SCORE (Systematic Coronary Risk Evaluation) risk function, ${ }^{7}$ which is approximately equal to $18 \%$ risk on the

\section{How this fits in}

A substantial part of prevention for cardiovascular diseases is delivered in primary care. According to the Dutch guideline for cardiovascular risk management, the heavy workload of this prevention for GPs could be shared with practice nurses. A prospective pragmatic randomised trial was used to investigate the effectiveness of practice nurses acting as substitutes for GPs in cardiovascular prevention, in daily practice. The findings of this study support the involvement of practice nurses in cardiovascular risk management in Dutch primary care.

Framingham scale., ${ }^{5,6}$ Patients with CVD were included, as these patients are at markedly increased risk of progression of the disease and of new manifestations. These patients were enrolled by specific 'International Classification of Primary Care' codes in the GPs' electronic patient record. ${ }^{5}$ Cardiovascular risk management for these patients is classified as secondary prevention. Patients without CVD were selected, who were possibly at high risk, depending on the level of total cholesterol, systolic blood pressure, and smoking behaviour, related to age and sex (Box 1). These patients were retrieved from electronic patient records according to whether they had systolic blood pressure $\geq 140 \mathrm{mmHg}$ or total cholesterol

\section{Box 1. Criteria for high-risk patients. ${ }^{a}$}

\section{Inclusion}

- Patients with cardiovascular disease: K74 'ischaemic heart disease with angina', ${ }^{\text {b }}$ K75 'acute myocardial infarction', , K76 'ischaemic heart disease without angina', ${ }^{\text {, K } 87}$ 'hypertension, complicated', ${ }^{\text {b }} \mathrm{K} 89$ 'transient cerebral ischaemia', ${ }^{\mathrm{b}} \mathrm{K} 90$ 'stroke/cerebrovascular accident', ${ }^{\text {b }} \mathrm{K} 92$ 'peripheral arterial disease', ${ }^{\mathrm{b}} \mathrm{K} 99$ 'other cardiovascular diseases (aortic aneurysm)', ${ }^{\text {b }}$ medical label 'CVD'

- Patients without cardiovascular disease (potentially high-risk): K86 'hypertension, uncomplicated', , T93 'high blood cholesterol', , systolic blood pressure $\geq 140 \mathrm{mmHg}$, total cholesterol $\geq 6.5 \mathrm{mmol} / \mathrm{l}$, medical label 'HY' (hypertension)

Exclusion

- Visiting cardiovascular specialist more than once a year, diabetes, outside age range 30-74 years, severe comorbidity, involved in other study on cardiovascular diseases, low 10-year risk of fatal cardiovascular disease ( $<10 \%$ SCORE)

Elevated risk factors ${ }^{c}$

- Systolic blood pressure $\geq 140 \mathrm{mmHg}$

- Total cholesterol $\geq 5 \mathrm{mmol} / \mathrm{l}$

- Low-density lipoprotein cholesterol $\geq 2.5 \mathrm{mmol} / \mathrm{l}$

- Smoker

- Body mass index $\geq 25 \mathrm{~kg} / \mathrm{m}^{2}$

aSCORE (Systematic Coronary Risk Evaluation) $\geq 10 \%$ compared to $18 \%$ on the Framingham scale. ${ }^{b}$ International Classification of Primary Care. ${ }^{\circ} D$ utch guideline for cardiovascular risk management. ${ }^{5}$ 


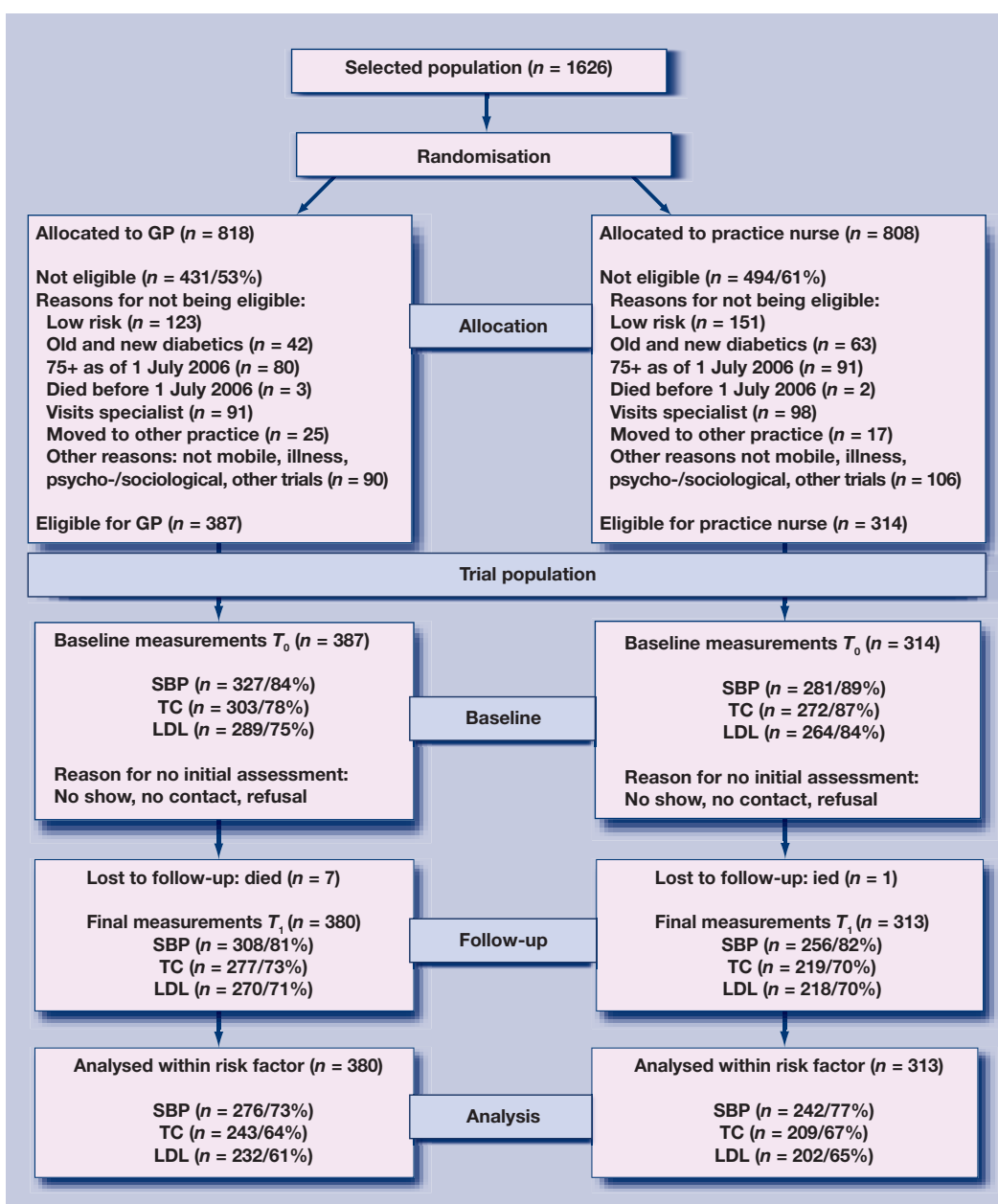

SBP = systolic blood pressure. $T C=$ total cholesterol. $L D L=$ low-density lipoprotein cholesterol

Figure 1. Design of trial. $\geq 6.5 \mathrm{mmol} / \mathrm{l}$, measured in the 6 months before selection. Such patients could be included after initial assessment if they were found to meet the $10 \%$ 10-year risk SCORE. ${ }^{7}$ Cardiovascular risk management for these patients is classified as primary prevention. Exclusion criteria for both groups were: visiting a cardiovascular specialist more than once per year, diabetes (as those patients were already being treated by a practice nurse), and severe comorbidity.

\section{Sample size and statistical analyses}

Initially, and based on practice nurse capacity, 1626 patients were randomly allocated to the GP group or the practice nurse group. The overall distribution of patients was $50 \%$ in each study group. In the individual healthcare centres, the imbalance in the number of patients among the two groups could vary between $35 \%$ and $65 \%$, depending on the available practice nurse capacity.

An exclusion rate of $40-60 \%$ was expected. With 700 patients, 350 patients in each group, a statistically significant difference could be found between the study groups, of $5.3 \mathrm{mmHg}$ in average systolic blood pressure (4\% of mean systolic blood pressure, mean $=140 \mathrm{mmHg}$ standard deviation $[S D]=20 \mathrm{mmHg}$ ) and $0.29 \mathrm{mmol} / \mathrm{l}$ in mean total cholesterol $(6 \%$ of mean total cholesterol, $5 \mathrm{mmol} / \mathrm{l}$, $\mathrm{SD}=1.2$ ) at a two-tailed $P=0.05$ significance level with $90 \%$ power. $^{20,21}$ As the EUROASPIRE II (European Action on Secondary and Primary Prevention through Intervention to Reduce Events) study assumes a difference of at least $5 \%$ mean reduction in systolic blood pressure and a $10 \%$ reduction in mean total cholesterol after 1 year of follow-up as clinically relevant, the sample size in the current study can be considered sufficient. ${ }^{22-24}$ For all statistical analyses, two-tailed testing was used. Differences between the groups were analysed by $\chi^{2}$ test for categorical data and by $t$-test for continuous data. Logistic regression analysis was used for detecting factors relating to missing measurements on systolic blood pressure and total cholesterol at baseline and follow-up. For each risk factor the effectiveness of the intervention was calculated with univariate analysis of variance. SPSS (version 15.0) was used for randomisation and data analysis.

\section{Cardiovascular risk management}

It was assumed that GPs and practice nurses were adhering to the Dutch guideline on cardiovascular risk management. Before July 2006, they were informed about this guideline. Practice nurses received further training on CVD, motivational interviewing, and shared decision making.

For initial assessment, all patients were invited by the healthcare centre for measurement of lipids and blood pressure, with the exception of those patients of the GP group who had undergone these measurements in the previous 6 months. A blood sample was taken from every patient and sent to a regional hospital laboratory. Measurement of blood pressure was performed by the practice assistant or by the practice nurse using standardised techniques. GPs were not involved.

Patients in the practice nurse group had a consultation with the practice nurse for assessment of other risk factors, and a 3-monthly monitoring schedule was set up for patients, but was adjusted individually according to the risk profile, (co)morbidity, and patient preferences. ${ }^{5}$ Patients could be referred to other professionals, such as a dietician. The GP group received a brief questionnaire to assess data about BMI and smoking behaviour at baseline. To validate selfreported answers by the GP group, half of the practice nurse group received an identical questionnaire.

After 1 year of follow-up, all patients were 
measured again for lipids and blood pressure. In addition, they received a questionnaire about treatment, compliance, referrals, risk factors, and satisfaction with care.

\section{RESULTS}

\section{Characteristics}

For this study, 1626 patients were randomised to the GP group or the practice nurse group. Of the selected patients, $43 \%$ met the inclusion criteria. The final study population consisted of 701 patients (Figure 1).

The most frequent reasons for exclusion were: ' $<10 \%$ 10-year risk SCORE for patients without CVD', 'visiting a cardiovascular specialist more often than once a year', 'aged $\geq 75$ years', and 'diabetes'.

No significant differences were found in baseline characteristics between the GP and practice nurse groups, in either the identified population or the trial population (Table 1).

\section{Treatment targets and results}

Many high-risk patients did not meet the treatment targets and had elevated risk factors at initial assessment (Box 1): $56 \%$ for systolic blood pressure, $48 \%$ for total cholesterol, $67 \%$ for low-density lipoprotein (LDL)-cholesterol, 74\% for BMI, and 31\% were smokers (missing values excluded).

A decrease in the mean level of risk factors after 1 year was found in both groups, but a larger decrease took place in the practice nurse group (Table 2). Only a small number of smokers stopped
Table 1. Characteristics of patients at baseline.

\begin{tabular}{lccc} 
& Total & GP group & $\begin{array}{c}\text { Practice } \\
\text { nurse group }\end{array}$ \\
\hline Identified population, $n$ & 1626 & 818 & 808 \\
\hline Age in years, mean (SD) $^{\mathrm{a}}$ & $64(9)$ & $64(9)$ & $64(9)$ \\
\hline$\%$ Male & 60 & 62 & 58 \\
\hline$\%$ Secondary prevention & 71 & 74 & 68 \\
\hline Study population, $n$ & 701 & 387 & 314 \\
\hline Age in years, mean (SD) $^{\mathrm{a}}$ & $64(8)$ & $63(8)$ & $64(8)$ \\
\hline \% Male $^{\mathrm{a}}$ & 64 & 65 & 62 \\
\hline \% Secondary prevention $^{\mathrm{a}}$ & 91 & 91 & 91 \\
\hline
\end{tabular}

${ }^{a}$ No significant differences between GP and practice nurse groups (Pearson $\chi^{2} /$ t-test $95 \%$, two-tailed).

smoking: $4 \%$ of smokers in the GP group (4/102) and $6 \%$ in the practice nurse group (4/67).

Figure 2 presents, from a univariate analysis of variance, the estimated marginal mean of each risk factor after 1 year for the GP group and the practice nurse group, for all patients (left side of each risk factor in Figure 2) and for patients with elevated value at baseline (right side). The marginal mean is controlled for healthcare centre, baseline risk factors, and other confounders. A significant estimated mean difference by study group was only found for total cholesterol. Practice nurses achieved better results for total cholesterol after 1 year of follow-up: the marginal mean was estimated at 4.8 $\mathrm{mmol} / \mathrm{l}$ at final assessment, whereas for the GP group it was $5.0 \mathrm{mmol} / \mathrm{l}(P=0.009)$. For patients

\section{Table 2. Mean level of risk factors within high-risk patients, not controlled for confounding.}

\begin{tabular}{|c|c|c|c|c|}
\hline & \multicolumn{2}{|c|}{$\begin{array}{c}\text { GP group, } \\
\text { mean }(95 \% \mathrm{Cl}), n\end{array}$} & \multicolumn{2}{|c|}{$\begin{array}{l}\text { Practice nurse group, } \\
\text { mean }(95 \% \mathrm{Cl}), n\end{array}$} \\
\hline & Baseline $\left(T_{0}\right)$ & After 1 year $\left(T_{1}\right)$ & Baseline $\left(T_{0}\right)$ & After 1 year $\left(T_{1}\right)$ \\
\hline \multicolumn{5}{|c|}{ Systolic blood pressure, $\mathrm{mmHg}$} \\
\hline All patients & 143 (140 to 145$), 327$ & 141 (138 to 143 ), 308 & 140 (138 to 142 ), 281 & 137 (135 to 139 ), 256 \\
\hline $\begin{array}{l}\text { Patients with high } \\
\text { systolic blood pressure } \\
\left(\geq 140 \mathrm{mmHg} \text { ) at } T_{0}\right.\end{array}$ & 157 (154 to 159$), 193$ & 150 (146 to 153 ), 163 & 155 (153 to 158 ), 146 & 144 (141 to 147$), 126)$ \\
\hline \multicolumn{5}{|l|}{ Total cholesterol, mmol// } \\
\hline All patients & 5.0 (4.9 to 5.1$), 302$ & 5.1 (4.9 to 5.2), 277 & 5.1 (5.0 to 5.3$), 272$ & 4.9 (4.7 to 5.0$), 219$ \\
\hline $\begin{array}{l}\text { Patients with high total } \\
\text { cholesterol }(\geq 5 \mathrm{mmo} / \mathrm{l}) \text { at } \mathrm{T}\end{array}$ & 5.9 (5.8 to 6.0$), 144$ & 5.6 (5.4 to 5.7$), 114$ & 6.1 (5.9 to 6.3 ), 133 & 5.3 (5.1 to 5.5), 102 \\
\hline \multicolumn{5}{|l|}{ LDL cholesterol, mmol/l } \\
\hline All patients & 3.0 (2.9 to 3.1$), 289$ & 3.1 (2.9 to 3.2 ), 270 & 3.1 (2.9 to 3.2), 264 & 2.9 (3.0 to 3.3), 218 \\
\hline $\begin{array}{l}\text { Patients with high } \mathrm{LDL} \\
\text { cholesterol }(\geq 2.5 \mathrm{mmol} / \mathrm{l}) \text { at }\end{array}$ & $\begin{array}{l}3.5 \text { (3.4 to 3.7), } 189 \\
\mathrm{t} \mathrm{T}_{0}\end{array}$ & 3.3 (3.1 to 3.4$), 148$ & 3.6 (3.4 to 3.7$), 180$ & 3.1 (3.0 to 3.3 ), 131 \\
\hline \multicolumn{5}{|l|}{$\mathrm{BMI}, \mathrm{kg} / \mathrm{m}^{2}$} \\
\hline All patients & 26.9 (26.4 to 27.4$), 248$ & 27.0 (26.5 to 27.5$), 281$ & 28.0 (27.5 to 28.5$), 251$ & 27.6 (27.1 to 28.1$), 235$ \\
\hline $\begin{array}{l}\text { Patients with } \\
\text { high } \mathrm{BMl}\left(\geq 25 \mathrm{~kg} / \mathrm{m}^{2}\right) \text { at } \mathrm{T}_{0}\end{array}$ & 28.7 (28.2 to 29.1$), 171$ & 28.4 (27.9 to 28.8$), 168$ & 29.3 (28.8 to 29.8 ), 199 & 28.9 (28.4 to 29.4 ), 176 \\
\hline
\end{tabular}

Treatment targets, Dutch guideline for cardiovascular risk management. ${ }^{5} L D L=$ low-density lipoprotein. $B M I=$ body mass index. 
Figure 2. Estimated marginal mean of each risk factor after 1 year between practice nurse group and GP group from univariate analysis of variance, ${ }^{a}$ a controlled for healthcare centre (HCC) baseline risk factor, and other predictors.

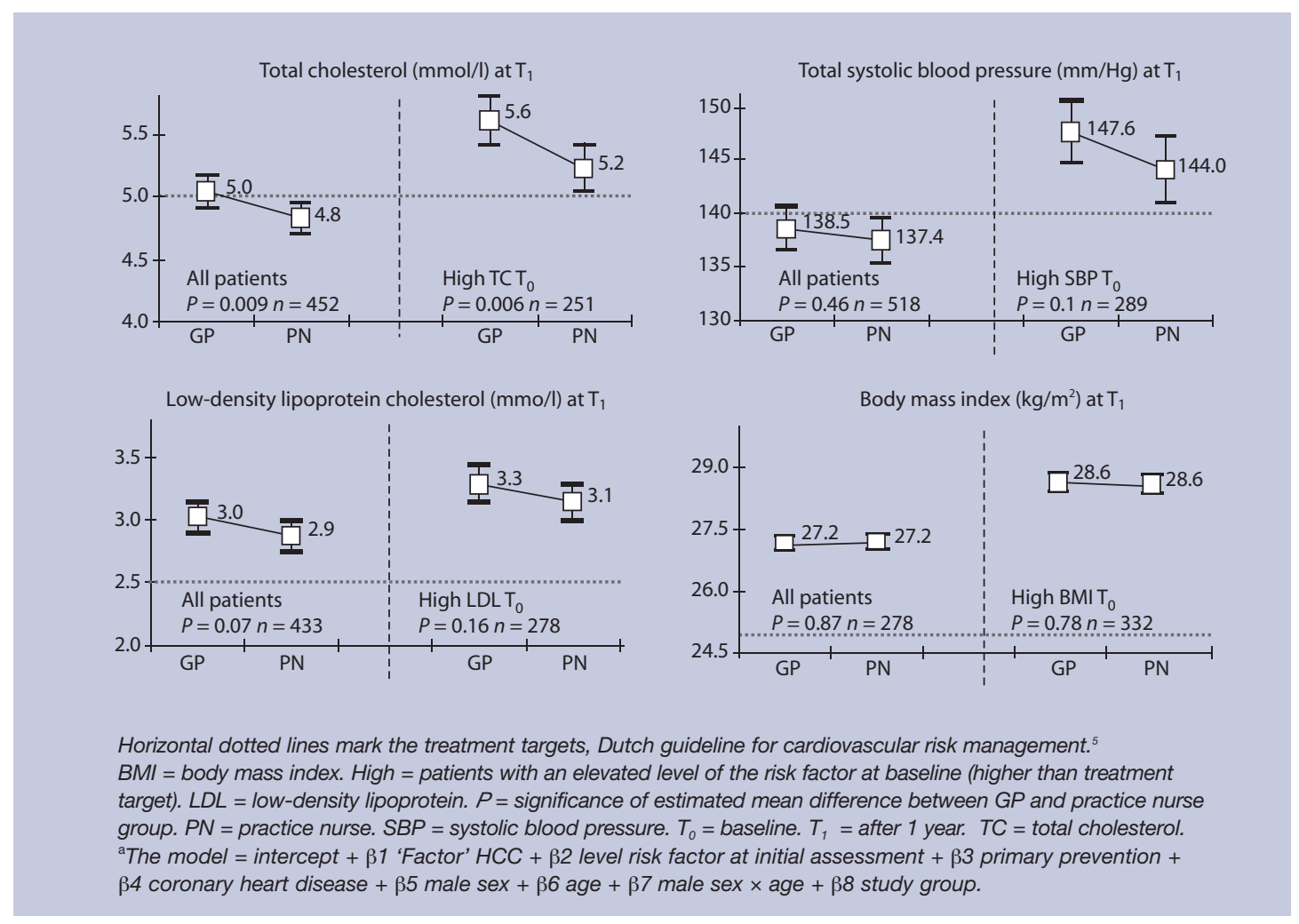

with an elevated total cholesterol at baseline, the estimated marginal mean was $5.2 \mathrm{mmol} / \mathrm{l}$ in the practice nurse group compared to $5.6 \mathrm{mmol} / \mathrm{l}$ in the GP group $(P=0.006)$.

\section{Missing measurements}

Of the trial population, $83 \%$ had measurements of lipids and blood pressure at baseline. Logistic regression analysis was used for detecting factors relating to missing values of systolic blood pressure and total cholesterol. As independent variables, study group, age, sex, prevention group, and coronary heart disease were entered into a backward stepwise procedure, while healthcare centre was always retained in the model. For total cholesterol, more missing measurements at baseline were found in the GP group (odds ratio $[\mathrm{OR}]=1.76$, $P=0.05)$. For systolic blood pressure, more missing values at baseline were found among males $(\mathrm{OR}=$ 1.7, $P=0.03$ ). At follow-up, missing values for total cholesterol were associated with increasing age (OR $=1.03, P=0.05)$ and with missing values of total cholesterol at baseline (OR $=6.9, P=0.05)$. For systolic blood pressure, association with missing values at follow-up was also found with increasing age $(\mathrm{OR}=1.03, P=0.006)$ and with missing systolic blood pressure at baseline ( $\mathrm{OR}=5.7, P=0.001)$. For total cholesterol and for systolic blood pressure, no significant relationship was detected between normal or elevated value at baseline and missing measurements at follow-up.

\section{DISCUSSION}

\section{Summary of main findings}

This study found a decrease in the mean level of risk factors in high-risk patients after 1 year of cardiovascular risk management. A larger decrease took place in the practice nurse group. A significant estimated mean difference by study group was only found for total cholesterol. In addition, more missing measurements of total cholesterol were found in the GP group; this may indicate that practice nurses are better at following the Dutch guideline for cardiovascular risk management than GPs. In a process evaluation of care among participating healthcare professionals, it was found that practice nurses were more familiar with treatment targets for risk factors than GPs.

\section{Strengths and limitations of the study}

The greatest strength of this pragmatic trial is that it gives evidence of effectiveness of cardiovascular risk management in day-to-day clinical practice. In addition, the large sample size ensured that those patients included were representative of the GP population. Furthermore, no dropout took place among the participating healthcare centres. Following this trial, five of the six centres continued to employ practice nurses for cardiovascular risk management.

The study also has limitations. First, it is limited to patients with a risk of at least $10 \%$ on the SCORE function, ${ }^{7}$ whereas the Dutch guideline for 
cardiovascular risk management suggested treatment at $5 \% .{ }^{5}$ This is due to the previous studies in the region, ${ }^{16,25,26}$ where high-risk patients with at least $20 \%$ on the Framingham scale were selected, as it had been argued that high-risk patients will benefit most from preventive strategies. ${ }^{9}$

Second, post-randomisation exclusion took place while information about the exclusion criteria was not always available before initial assessment. It was decided not to randomise patients after passing the inclusion criteria because otherwise the practice nurse group would have to visit the centre twice, and this would have meant asking too much of patients. The difference in exclusion rates between the groups (53\% versus $61 \%$ ) might be slightly suspect. However, of all the exclusion criteria, only 'diabetics' and 'other reasons' (Figure 1) might have been influenced by the study group, because of the more systematic treatment by the practice nurse. Because the baseline characteristics of the study groups are the same, risking bias in the analyses is not expected..$^{27}$

The third limitation of the study is that smoking behaviour and BMI were partly self-reported, mostly in the GP group. This could be considered a limitation, but the notion of poor reliability of selfreported smoking history was contradicted by a meta-analysis in which the sensitivity was found to be $88 \%$ and the specificity $89 \% .^{28}$ For BMI, a significant correlation between self-reported and recorded values was found $(P<0.01)$; this is also confirmed by other studies. ${ }^{29}$ Self-reported weight in the GP group was corrected with a factor of 1.011 .

Fourth, the intervention was directed at healthcare centres, with the result that some transfer of effect from the practice nurse to the GP might have taken place, resulting in reduced effectiveness. However, since 2006, much attention has been paid to cardiovascular prevention in primary care by Dutch medical and patient organisations, the government, and the Dutch Heart Foundation. ${ }^{30}$

Finally, the results will depend on the individual experiences of GPs and practice nurses who cooperated in the trial. Most GPs in this trial were already acquainted with risk management, while this task is new for practice nurses. It is therefore expected that, in the future experienced practice nurses will be achieving even better health outcomes than found in the present trial.

\section{Comparison with existing literature}

A recent Australian review on the efficacy of practice nurses for cardiovascular prevention has also shown improved results for cholesterol, blood pressure, and weight. ${ }^{31}$ Similar conclusions were drawn in the EuroAction survey, partly focusing on primary prevention by practice nurses for patients with $\geq 5 \%$ risk, ${ }^{7}$ and for their families. ${ }^{23}$ Other studies on nurseled secondary prevention in primary care show similar results. ${ }^{32,33}$

No difference was found in patient characteristics between the participants and the non-attenders, although more missing measurements were found among males and older people. This finding corresponds with other studies: low blood pressure control is associated with increasing age, male sex, low education, non-white race, previous CVDs, living alone, decreased physical activity, or depression..$^{34,35}$

Many high-risk patients did not achieve the treatment targets for the risk factors. The proportion is comparable with data from the Dutch Heart Foundation, ${ }^{36}$ and the EUROASPIRE studies. ${ }^{37}$ Comparison of the study population with data from the Registration Network Family Practices of Maastricht University Medical Centre reveals a similar distribution of sex and age. ${ }^{38}$

In the present study, patients received a postal invitation from the healthcare centre for risk assessment. Although this is not common in primary care in the Netherlands, the response rate was high: $83 \%$ and $75 \%$ of the patients had lipids and blood pressure measured at initial and final assessment. This is comparable with the $70 \%$ attendance rates in response to invitations by the national prevention programme for influenza, breast cancer, and cervical cancer. ${ }^{39}$

\section{Implications for future research and clinical practice}

The present findings support the involvement of practice nurses in cardiovascular risk management at the primary care level in the Netherlands. Because of the high and increasing volume of patients requiring cardiovascular risk management, this finding is likely to have important implications nationally for the organisation of primary care cardiovascular prevention. As many patients still did not achieve the treatment targets, cardiovascular risk management should be improved. Research is needed into the improvement and long-term effect of cardiovascular risk management, with a focus on reaching non-attenders and decreasing the patient dropout rate.

\section{Funding body}

The study was funded by University Hospital Maastricht and partly supported by an unrestricted educational Pfizer grant. The practice nurses were funded by healthcare insurance companies (VGZ/CZ) and by Beyaert Robuust Limburg, reference: E06EL17

\section{Ethics committee}

The Medical Ethical Committee of the University of Maastricht agreed to the research being implemented. Privacy of the participating patients was respected. After 
1 year, all patients were asked for their consent (reference: METC/A06-007)

\section{Competing interests}

The authors have stated that there are none

\section{Acknowledgements}

We gratefully acknowledge the participation of all patients and health centre staff who cooperated in this research.

\section{Discuss this article}

Contribute and read comments about this article on the Discussion Forum: http://www.rcgp.org.uk/bjgp-discuss

\section{REFERENCES}

1. World Health Organization. Cardiovascular diseases. Geneva: World Health Organization.

http://www.who.int/cardiovascular_diseases/en/ (accessed 26 Aug 2009).

2. Vaartjes I, Peters RJG, van Dis SJ, Bots M. Cardiovascular diseases in the Netherlands 2008 [in Dutch]. The Hague: Dutch Heart Foundation, 2008

3. Centraal Bureau voor de Statistiek. Statistics Netherlands. http://www.cbs.nl (accessed 26 Aug 2009).

4. De Backer G, Ambrosioni E, Borch-Johnsen K, et al. European guidelines on cardiovascular disease prevention in clinical practice: third joint task force of European and other societies on cardiovascular disease prevention in clinical practice. Eur I Cardiovasc Prev Rehabil 2003; 10(4): S1-S10.

5. Dutch Institute for Healthcare Improvement $(\mathrm{CBO})$ and Dutch College of General Practitioners (NHG). Dutch guideline for cardiovascular risk management. Utrecht: Dutch Institute fo Healthcare Improvement CBO and Dutch College of General Practitioners, 2006.

6. Anderson KM, Wilson PW, Odell PM, Kannel WB. An updated coronary risk profile. A statement for health professionals. Circulation 1991; 83(1): 356-362.

7. Conroy RM, Pyorala K, Fitzgerald AP, et al. Estimation of ten-year risk of fatal cardiovascular disease in Europe: the SCORE project. Eur Heart J 2003; 24(11): 987-1003.

8. Assmann G, Cullen P, Schulte H. Simple scoring scheme for calculating the risk of acute coronary events based on the 10-year follow-up of the prospective cardiovascular Munster (PROCAM) study. Circulation 2002; 105(3): 310-315

9. Wood D, De Backer G, Faergeman O, et al. Prevention of coronary heart disease in clinical practice. Summary of recommendations of the Second Joint Task Force of European and other Societies on Coronary Prevention. J Hypertens 1998; 16(10): 1407-1414.

10. Van den Berg M, de Bakker D. Introduction of advanced practice nursing in Dutch primary care [in Dutch]. Utrecht: NIVEL, 2003

11. Meulepas MA, Jacobs JE, Lucas AE, et al. The feasibility of a primary care model for the management of COPD. Prim Care Respir I 2006; 15(6): 337-341.

12. Van Son L, Crebolder H, van Hoef L, Beusmans G. Supporting the GP [in Dutch]. Huisarts Wet 2004; 47(1): 15-21.

13. Aubert RE, Herman WH, Waters J, et al. Nurse case management to improve glycemic control in diabetic patients in a health maintenance organization. A randomized, controlled trial. Ann Intern Med 1998; 129(8): 605-612.

14. Horrocks S, Anderson E, Salisbury C. Systematic review of whether nurse practitioners working in primary care can provide equivalent care to doctors. BMJ 2002; 324(7341): 819-823.

15. Laurant M, Reeves D, Hermens R, et al. Substitution of doctors by nurses in primary care. Cochrane Database Syst Rev 2005; (2): CD001271.

16. Leenders F, Beusmans G, Swerts $\mathrm{H}$, et al. A practice nurse for patients with cardiovascular diseases, an explorative study [in Dutch]. Tijdschr Praktijkond 2006; 1(2): 45-50.

17. Zelen M. A new design for randomized clinical trials. N Engl J Med 1979; 300(22): 1242-1245.

18. Schellings R, Kessels AG, Ter Riet G, et al. Indications and requirements for the use of prerandomization. J Clin Epidemiol 2009; 62(4): 393-399.

19. Torgerson DJ, Roland M. What is Zelen's design? BMJ 1998 316(7131): 606 .

20. Ebrahim S, Smith GD. Systematic review of randomised controlled trials of multiple risk factor interventions for preventing coronary heart disease. BMJ 1997; 314(7095): 1666-1674.

21. Martin TN, Irving RJ, Sutherland M, et al. Improving secondary prevention in coronary bypass patients: closing the audit loop. Heart 2005; 91(4): 456-459.

22. EUROASPIRE. Lifestyle and risk factor management and use of drug therapies in coronary patients from 15 countries; principal results from EUROASPIRE II Euro Heart Survey Programme. Eur Heart J 2001; 22(7): 554-572.

23. Wood DA, Kotseva K, Connolly S, et al. Nurse-coordinated multidisciplinary, family-based cardiovascular disease prevention programme (EUROACTION) for patients with coronary heart disease and asymptomatic individuals at high risk of cardiovascular disease: a paired, cluster-randomised controlled trial. Lancet 2008; 371(9629): 1999-2012.

24. Pyorala K, Lehto S, De Bacquer D, et al. Risk factor management in diabetic and non-diabetic patients with coronary heart disease. Findings from the EUROASPIRE I AND II surveys. Diabetologia 2004; 47(7): 1257-1265.

25. Schuit AJ, Wendel-Vos GCW, Verschuren WMM, et al. Effect of 5 year community intervention Hartslag Limburg on cardiovascular risk factors. Am J Prev Med 2006; 30(3): 237-242.

26. Harting J, van Assema P, van Limpt $\mathrm{P}$, et al. Cardiovascular prevention in the Hartslag Limburg project: effects of a high-risk approach on behavioral risk factors in a general practice population. Prev Med 2006; 43(5): 372-378.

27. Fergusson D, Aaron SD, Guyatt G, Hebert P. Post-randomisation exclusions: the intention to treat principle and excluding patients from analysis. BMJ 2002; 325(7365): 652-654.

28. Patrick DL, Cheadle A, Thompson DC, et al. The validity of selfreported smoking: a review and meta-analysis. Am J Public Health 1994; 84(7): 1086-1093.

29. McAdams MA, Van Dam RM, Hu FB. Comparison of self-reported and measured BMI as correlates of disease markers in US adults. Obesity (Silver Spring) 2007; 15(1): 188-196.

30. Nielen MMJ, Schellevis FG. Prevention in primary care in 2008 [in Dutch]. Utrecht: NIVEL, 2008.

31. Caruana E. Effectiveness of general practice nurse interventions in cardiac risk factor reduction among adults. J Adv Nurs 2008; 62(5): 530-531.

32. Khunti K, Stone M, Paul S, et al. Disease management programme for secondary prevention of coronary heart disease and heart failure in primary care: a cluster randomised controlled trial. Heart 2007; 93(11): 1398-1405.

33. McDonnell A, Crookes P, Davies S, Shewan J. Practice nurses and the prevention of cardiovascular disease and stroke: a literature review to promote evidence-based practice. Part I: rationale review methods, effectiveness of practice nurses and smoking cessation. Clin Eff Nurs 1997; 1(9): 189-197.

34. Danon-Hersch N, Marques-Vidal P, Bovet P, et al. Prevalence, awareness, treatment and control of high blood pressure in a Swiss city general population: the CoLaus study. Eur J Cardiovasc Prev Rehabil 2009; 16(1): 66-72.

35. Steinhagen-Thiessen E, Bramlage P, Lösch C, et al. Dyslipidemia in primary care - prevalence, recognition, treatment and control: data from the German Metabolic and Cardiovascular Risk Project (GEMCAS). Cardiovasc Diabetol 2008; 7: 31

36. Kaasjager HAH, van Dis SJ. Cardiovascular risks within patients with existing cardiovascular diseases [in Dutch]. The Hague: Dutch Heart Foundation, 2008.

37. Kotseva K, Wood D, De Backer G, et al. Cardiovascular prevention guidelines in daily practice: a comparison of EUROASPIRE I, II, and III surveys in eight European countries. Lancet 2009; 373(9667): 929-940.

38. Metsemakers JF, Knottnerus JA, van Schendel GJ, Kocken RI, Limonard CB. Unlocking patients' records in general practice for research, medical education and quality assurance: the Registration Network Family Practices. Int J Biomed Comput 1996; 42(1-2): $43-50$.

39. Busch MCM. Prevention in primary care [in Dutch]. Bilthoven: National Institute for Public Health and the Environment (RIVM). Volksgezondheid Toekomst Verkenning, Nationaal Kompas Volksgezondheid RIVM, 2005. 